\title{
Cell Therapy for Parkinson's Disease: New Hope from Reprogramming Technologies
}

\author{
Zhiguo Chen ${ }^{1,2,3, *}$ \\ ${ }^{1}$ Cell Therapy Center, Xuanwu Hospital, Capital Medical University, and Key Laboratory of Neurodegeneration, \\ Ministry of Education, Beijing, 100053, China \\ ${ }^{2}$ Center of Neural Injury and Repair and ${ }^{3}$ Center of Parkinson's Disease, Beijing Institute for Brain Disorders, Beijing, \\ China
}

[Received September 14, 2014; Revised December 1, 2014; Accepted December 1, 2014]

\begin{abstract}
Parkinson's disease (PD) is a neurodegenerative disease with the major pathology being the progressive loss of dopaminergic (DA) midbrain neurons in the substantia nigra. As early as in the 1980s, open-label clinical trials employing fetal ventral mesencephalon (fVM) tissues have demonstrated significant efficacy for PD treatment, which led to two NIH-sponsored double-blind placebo-controlled clinical trials. However, both trials showed only mild outcome. Retrospective analysis revealed several possible reasons that include patient selection, heterogeneity of grafts, immune recognition of grafts, lack of standardization of transplantation procedure and uneven distribution of grafts. Recent years have seen advances in reprogramming technologies which may provide solutions to the problems associated with fVM tissues. Induced pluripotent stem cells (iPSCs) and induced neural stem cells (iNSCs) hold promise for generating clinical grade DA neural cells that are safe, homogeneous, scalable and standardizable. These new technologies may bring back clinical trials using cell therapy for PD treatment in the future.
\end{abstract}

Key words: cell therapy, Parkinson's disease, reprogramming, dopaminergic neurons, clinical trials

Parkinson's disease (PD) is the second most common neurodegenerative disease in people over 60 years old [1, 2]. The major pathology of $\mathrm{PD}$ is the progressive degeneration of dopaminergic (DA) neurons located at the substantia nigra in midbrain, which send axonal projections to striatum and are involved in the circuits controlling motor functions. In addition to motor symptoms caused by degeneration of DA neurons, many PD patients also present with non-motor symptoms, such as cognitive impairment and mood problems [3].

To date, no disease modifying treatments exist in clinics. The current treatments mostly target the symptoms only. Pharmaceutical drugs, such as levodopa, catechol-O-methyl transferase, and monoamine oxidase inhibitors, aim at replenishing or stabilizing dopamine supply in striatum; Deep brain stimulation (DBS) normally works by electrically lesioning subthalamic nucleus (STN) or globus pallidus interna (GPi) to increase the collective motor output. However, neither of the above can stop nor reverse the progress of DA neuron degeneration in midbrain. Other emerging treatments that have gone through clinical trials include gene therapies and cell transplantation therapies. Through gene therapy, viral vectors encoding GAD, neurotrophic/growth factors, or enzymes sufficient for production of dopamine have been trialled or still underway [4-9]. In this short review, I will focus more on the cell therapy aspect of PD treatment. 


\section{Human fetal ventral mesencephalon (fVM) tissue transplantation for PD treatment}

In PD patients, the degenerating neurons are restricted in space and cell type - mainly DA neurons at the substantia nigra are injured; this feature attracts the interest of cell biologists and makes PD a feasible disease for cell transplantation therapy. In adult brain, it is very difficult to reconstruct the nigro-striatal circuit. DA neurons placed at the substantia nigra lack the appropriate microenvironment to send their axons into the striatum. Instead, dopamine-producing tissues/cells were engrafted at striatum in order to replenish dopamine supply. Since the 1980s, various cell sources have been tested, which include autografts of adrenal medulla, sympathetic ganglion, carotid body-derived cells, xenografts of fetal porcine ventral mesencephalon, and allografts of human fetal ventral mesencephalon (fVM) tissues [1, 10-14]. Among them, the most successful were the studies employing fVM tissues. In the initial open-label trials, PD patients receiving fVM tissues showed steady improvement in symptoms and survival of functional grafts as evidenced by PET imaging [14-20]. The encouraging results led to two double-blind clinical trials sponsored by National Institutes of Health $(\mathrm{NIH})$ in the United States [21, 22]. Disappointingly, both trails failed to meet the primary end points. Although a subpopulation of patients showed significant improvement, as a whole, no statistical significance was observed. Even worse was that, for the first time, graft-induced dyskinesias (GID) was found in $15-50 \%$ of the engrafted patients. Since then, clinical trials using fVM tissues/cells have come to a standstill. Careful retrospective analysis revealed several possible reasons for the mild outcome. The subpopulation that responded well to fVM transplantation were relatively younger patients at an early stage of PD who remained responsive to levodopa treatment [23, 24]. It seems certain numbers of remaining endogenous nigrostriatal innervations are necessary for fVM grafts to exert significant functions. Another possible reason was the immune recognition of incoming grafts. Although the brain is a relatively immune privileged organ, allogeneic neural grafts may still elicit innate and adaptive immune signaling, which can influence transplantation outcomes [25-27]. In one of the two double-blind clinical trials, immunosuppressant cyclosporine was administered two weeks before and through six months after transplantation [21]. Patients experienced improvement in motor functions until the withdrawal of immunosuppression, at which time the patients' symptoms started to deteriorate. The coincidence in timing suggests that allograft-induced immune recognition plays an important role. The mechanisms underlying GID still remain unclear. One possibility was that the uneven distribution of grafts resulted in unbalanced innervations and formation of "hot spots", leading to pulsatile stimulations. Another possibility was that midbrain grafts were heterogeneous; they contained not only DA neurons but also other neuronal subtypes, such as serotonergic neurons. Serotonergic neurons can convert levodopa to dopamine and release it as a "false" transmitter. However, serotonergic neurons lack the autoregulatory mechanism to control the extracellular level of dopamine; this "uncontrolled" release of dopamine may contribute to levodopa-induced dyskinesia, but cannot explain why GID still existed after a complete withdrawal of levodopa in engrafted patients. However, that administration of 5HT1A agonist buspirone can relieve GID in transplanted patients indicates a significant role of serotonergic neurons in GID [28, 29]. In addition, the aggravation in GID following discontinuation of immunosuppression suggests the involvement of immune signaling in GID [21].

\section{iPSC-derived dopaminergic cells}

The above problems associated with transplantation of fVM tissues/cells are two folds: recipients and donor cells. Selection of patients at a relatively early stage of PD without severe non-motor symptoms may give a better outcome. The ideal donor cells would be autologous homogeneous dopaminergic cells which are safe and standardizable. However, this has been impossible until the advent of recent reprogramming technologies, which may provide solutions to the donor cell problems. In 2006 and 2007, Yamanaka and colleagues reported the conversion of mouse and human fibroblasts into embryonic stem cell - like cells, namely induced pluripotent stem cells (iPSCs) [30, 31]. Due to these ground-breaking findings, Yamanaka was awarded Nobel Prize in 2012. iPSCs can be derived from patients' own somatic cells and thus have identical or almost identical genetic background. As donor cells, iPSC-derived DA neurons may circumvent or greatly reduce the adverse effects of allograft-associated immune responses. The conventional way to induce iPSCs involves use of integrative viral vectors and fibroblasts as starter cells. With technological advancement, now iPSCs can be obtained using non-integrative (transgene free) methods [32-37] from relatively more accessible tissues/cells, such as blood cells [38]. iPSCs can be passaged extensively in vitro and this great expandability makes it easy to meet the scalability requirements for clinical applications. Theoretically, with infinitely expandable iPSCs to start the differentiation process, even if the efficiency for DA neuron production is low, sufficient number of donor cells may be generated to meet the transplantation purposes. Also, another advantage with a potentially large number 
of iPSCs is that there are ample cells for further enrichment and manipulation, such as magnetic cell sorting or flow cytometry, a procedure that normally incurs significant cell loss. One problem associated with the great proliferative capacity is the risk to develop tumors. Two strategies can be used separately or in combination to reduce the tumor risks. The first, is to improve paradigms to robustly differentiate the iPSCs towards specific neural subtypes. Normally, the extent of differentiation correlates inversely to the tumorigenic capacity along the course of iPSC specification. Treating monolayer iPSCs with small molecules, such as SB431542 and CHIR99021, may be an option to enhance the robustness of differentiation. The second, is to remove the residual pluripotent tumorigenic stem cells and enrich for neural subtypes. NCAM has been used as a surface marker to enrich for neural cells [39] and Corin as a marker to select for DA neurons over serotonergic neurons [40-42]. However, a single marker may not be enough to accurately isolate pure DA neurons. Future work is needed to identify more positive and/or negative surface markers to ensure homogeneous population of DA neurons. iPSCs hold great promise to produce autologous homogeneous DA neural cells for safe and efficacious treatment of PD. Encouraged by the approval of clinical trial which plans to use iPSC-derived retinal pigment epithelium (RPE) cell sheets to treat patients with exudative (wet-type) age-related macular degeneration in Japan, the PD field is anticipating proof-of-principle results of autologous iPSC-derived DA cell transplantation in large PD animal models. If it works, we may hope to see phase I clinical trials in the future.

\section{Induced dopaminergic (iDA) neurons}

An alternative way to obtain autologous DA neurons is to directly reprogram somatic cells to DA neurons and thus bypassing pluripotent states. Wernig and colleagues have reported a direct conversion of fibroblasts to mature neurons by three factors, Ascl1, Brn2, and Myt11 or Zic1 [43]. However, these induced neurons (iNs) are mostly glutaminergic and GABAergic, and do not contain DA neurons. Our lab and collaborators used, in addition to Ascl1 and Brn2, eight key factors that play central roles in the specification of dopaminergic neurons, and successfully generated induced dopaminergic (iDA) neurons from mouse fibroblasts [44]. Then we tried to reduce the number of factors and achieved a 5-factor combination that can induce iDA neurons with relatively higher efficiency. Other groups have also reported iDA neurons converted from mouse and human somatic cells using slightly different combinations of factors [45-48]. It seems those key DA neuron factors may be involved in a regulatory network and one factor would affect another.
iDA neurons could offer a valuable platform to study patient-specific (particularly familial PD patients) DA neurons to better our understanding of disease mechanisms and to facilitate drug screening. However, mature neurons normally have difficulty surviving transplantation processes and may not suit well cell therapy purposes.

\section{Induced neural stem cells (iNSCs)}

Compared to iNs, adult neural stem cells (NSCs) or neural progenitor cells (NPCs) with the potential of DA neuron specification may be a suitable cell source for engraftment. Inspired by the iPSC and iN work, our lab and collaborators tested the hypothesis of reprogramming mouse somatic cells directly to NSC-like cells. Using eight or nine factors, we generated induced NSCs (iNSCs) from mouse sertoli cells and tail-tip fibroblasts [44, 49]. These iNSCs can self-renew and differentiate to different neuronal subtypes including DA neurons. Importantly, they can also survive transplantation and differentiate to neurons after being introduced into the dentate gyrus of adult hippocampus [49] or naïve and 6-OHDA-lesioned striatum of mice [50]. Other groups have also reported iNSCs converted from mouse and human somatic cells $[51,52]$. Compared to iPSCs, iNSCs represent less tumorigenic risk. However, iNSCs as well as most adult tissue stem cells, do not possess the extensively proliferative capacity, and this relatively limited scalability may need to be addressed in certain clinical context. In addition, whether iNSCs have efficacy in PD models remains to be illustrated. As a compromise, iNSCs/iNPCs can be obtained from the intermediate pluripotent cells during iPSC induction [53-56], by changing the medium to what can selectively support NSC growth. Pei and colleagues have managed to generate iNPCs from human urine epithelial-like cells by using this strategy [54]. These iNPCs exhibited primitive features with a good proliferative capacity, and could give rise to DA neurons in vitro [54]. It remains unclear whether these cells are safe and/or efficacious in PD animal models.

In summary, the reprogramming technologies have raised new hope for PD patients. Obtaining safe, homogeneous, scalable and standardizable DA neural cells would be a key to bringing cell therapy back to clinical trials for PD treatment in the foreseeable future.

\section{Acknowledgements}

Grant sponsors: National Basic Research Program of China (2011CB965103), National Natural Science Foundation of China $(31340075,31070946,81141014$, 81422014), and Beijing Natural Science Foundation 
(5142005).

\section{References}

[1] Buttery PC, Barker RA (2014). Treating Parkinson's disease in the 21 st century: can stem cell transplantation compete? J Comp Neurol, 522: 2802-2816

[2] Williams-Gray CH, Evans JR, Goris A, Foltynie T, Ban M, Robbins TW, et al. (2009). The distinct cognitive syndromes of Parkinson's disease: 5 year follow-up of the CamPaIGN cohort. Brain, 132: 2958-2969

[3] Chaudhuri KR, Healy DG, Schapira AH (2006). Nonmotor symptoms of Parkinson's disease: diagnosis and management. Lancet Neurol, 5: 235-245

[4] Kaplitt MG, Feigin A, Tang C, Fitzsimons HL, Mattis P, Lawlor PA, et al. (2007). Safety and tolerability of gene therapy with an adeno-associated virus (AAV) borne GAD gene for Parkinson's disease: an open label, phase I trial. Lancet, 369: 2097-2105

[5] Marks WJ, Jr., Ostrem JL, Verhagen L, Starr PA, Larson PS, Bakay RA, et al. (2008). Safety and tolerability of intraputaminal delivery of CERE-120 (adeno-associated virus serotype 2-neurturin) to patients with idiopathic Parkinson's disease: an open-label, phase I trial. Lancet Neurol, 7: 400-408

[6] Marks WJ, Jr., Bartus RT, Siffert J, Davis CS, Lozano A, Boulis N, et al. (2010). Gene delivery of AAV2-neurturin for Parkinson's disease: a double-blind, randomised, controlled trial. Lancet Neurol, 9: 1164-1172

[7] Bankiewicz KS, Forsayeth J, Eberling JL, SanchezPernaute R, Pivirotto P, Bringas J, et al. (2006). Longterm clinical improvement in MPTP-lesioned primates after gene therapy with AAV-hAADC. Mol Ther, 14: 564-570

[8] Azzouz M, Martin-Rendon E, Barber RD, Mitrophanous KA, Carter EE, Rohll JB, et al. (2002). Multicistronic lentiviral vector-mediated striatal gene transfer of aromatic L-amino acid decarboxylase, tyrosine hydroxylase, and GTP cyclohydrolase I induces sustained transgene expression, dopamine production, and functional improvement in a rat model of Parkinson's disease. J Neurosci, 22: 10302-10312

[9] Jarraya B, Boulet S, Ralph GS, Jan C, Bonvento G, Azzouz M, et al. (2009). Dopamine gene therapy for Parkinson's disease in a nonhuman primate without associated dyskinesia. Sci Transl Med, 1: 2ra4

[10] Arjona V, Minguez-Castellanos A, Montoro RJ, Ortega A, Escamilla F, Toledo-Aral JJ, et al. (2003). Autotransplantation of human carotid body cell aggregates for treatment of Parkinson's disease. Neurosurgery, 53: 321-328; discussion 328-330

[11] Backlund EO, Granberg PO, Hamberger B, Knutsson E, Martensson A, Sedvall G, et al. (1985). Transplantation of adrenal medullary tissue to striatum in parkinsonism. First clinical trials. J Neurosurg, 62: 169-173

[12] Itakura T, Uematsu Y, Nakao N, Nakai E, Nakai K (1997). Transplantation of autologous sympathetic ganglion into the brain with Parkinson's disease. Long-term follow-up of 35 cases. Stereotact Funct Neurosurg, 69: 112-115
[13] Schumacher JM, Ellias SA, Palmer EP, Kott HS, Dinsmore J, Dempsey PK, et al. (2000). Transplantation of embryonic porcine mesencephalic tissue in patients with PD. Neurology, 54: 1042-1050

[14] Lindvall O, Brundin P, Widner H, Rehncrona S, Gustavii B, Frackowiak R, et al. (1990). Grafts of fetal dopamine neurons survive and improve motor function in Parkinson's disease. Science, 247: 574-577

[15] Hagell P, Schrag A, Piccini P, Jahanshahi M, Brown R, Rehncrona S, et al. (1999). Sequential bilateral transplantation in Parkinson's disease: effects of the second graft. Brain, 122 ( Pt 6): 1121-1132

[16] Mendez I, Vinuela A, Astradsson A, Mukhida K, Hallett $\mathrm{P}$, Robertson H, et al. (2008). Dopamine neurons implanted into people with Parkinson's disease survive without pathology for 14 years. Nat Med, 14: 507-509

[17] Piccini P, Brooks DJ, Bjorklund A, Gunn RN, Grasby PM, Rimoldi O, et al. (1999). Dopamine release from nigral transplants visualized in vivo in a Parkinson's patient. Nat Neurosci, 2: 1137-1140

[18] Wenning GK, Odin P, Morrish P, Rehncrona S, Widner $\mathrm{H}$, Brundin $\mathrm{P}$, et al. (1997). Short- and long-term survival and function of unilateral intrastriatal dopaminergic grafts in Parkinson's disease. Ann Neurol, 42: 95-107

[19] Remy P, Samson Y, Hantraye P, Fontaine A, Defer G, Mangin JF, et al. (1995). Clinical correlates of [18F]fluorodopa uptake in five grafted parkinsonian patients. Ann Neurol, 38: 580-588

[20] Widner H, Tetrud J, Rehncrona S, Snow B, Brundin P, Gustavii B, et al. (1992). Bilateral fetal mesencephalic grafting in two patients with parkinsonism induced by 1methyl-4-phenyl-1,2,3,6-tetrahydropyridine (MPTP). N Engl J Med, 327: 1556-1563

[21] Olanow CW, Goetz CG, Kordower JH, Stoessl AJ, Sossi V, Brin MF, et al. (2003). A double-blind controlled trial of bilateral fetal nigral transplantation in Parkinson's disease. Ann Neurol, 54: 403-414

[22] Freed CR, Greene PE, Breeze RE, Tsai WY, DuMouchel W, Kao R, et al. (2001). Transplantation of embryonic dopamine neurons for severe Parkinson's disease. N Engl J Med, 344: 710-719

[23] Ma Y, Tang C, Chaly T, Greene P, Breeze R, Fahn S, et al. (2010). Dopamine cell implantation in Parkinson's disease: long-term clinical and (18)F-FDOPA PET outcomes. J Nucl Med, 51: 7-15

[24] Politis M, Lindvall O (2012). Clinical application of stem cell therapy in Parkinson's disease. BMC Med, 10: 1

[25] Chen Z, Palmer TD (2008). Cellular repair of CNS disorders: an immunological perspective. Hum Mol Genet, 17: R84-92

[26] Chen Z, Phillips LK, Gould E, Campisi J, Lee SW, Ormerod BK, et al. (2011). MHC mismatch inhibits neurogenesis and neuron maturation in stem cell allografts. PLoS One, 6: e14787

[27] Chen Z, Palmer TD (2013). Differential roles of TNFR1 and TNFR2 signaling in adult hippocampal neurogenesis. Brain Behav Immun, 30: 45-53

[28] Shin E, Tronci E, Carta M (2012). Role of Serotonin Neurons in L-DOPA- and Graft-Induced Dyskinesia in a 
Rat Model of Parkinson's Disease. Parkinsons Dis, 2012: 370190

[29] Petit GH, Olsson TT, Brundin P (2014). The future of cell therapies and brain repair: Parkinson's disease leads the way. Neuropathol Appl Neurobiol, 40: 60-70

[30] Takahashi K, Yamanaka S (2006). Induction of pluripotent stem cells from mouse embryonic and adult fibroblast cultures by defined factors. Cell, 126: 663-676

[31] Takahashi K, Tanabe K, Ohnuki M, Narita M, Ichisaka T, Tomoda K, et al. (2007). Induction of pluripotent stem cells from adult human fibroblasts by defined factors. Cell, 131: 861-872

[32] Kaji K, Norrby K, Paca A, Mileikovsky M, Mohseni P, Woltjen K (2009). Virus-free induction of pluripotency and subsequent excision of reprogramming factors. Nature, 458: 771-775

[33] Okita K, Hong H, Takahashi K, Yamanaka S (2010). Generation of mouse-induced pluripotent stem cells with plasmid vectors. Nat Protoc, 5: 418-428

[34] Soldner F, Hockemeyer D, Beard C, Gao Q, Bell GW, Cook EG, et al. (2009). Parkinson's disease patientderived induced pluripotent stem cells free of viral reprogramming factors. Cell, 136: 964-977

[35] Stadtfeld M, Nagaya M, Utikal J, Weir G, Hochedlinger $\mathrm{K}$ (2008). Induced pluripotent stem cells generated without viral integration. Science, 322: 945-949

[36] Woltjen K, Michael IP, Mohseni P, Desai R, Mileikovsky M, Hamalainen R, et al. (2009). piggyBac transposition reprograms fibroblasts to induced pluripotent stem cells. Nature, 458: 766-770

[37] Hou P, Li Y, Zhang X, Liu C, Guan J, Li H, et al. (2013). Pluripotent stem cells induced from mouse somatic cells by small-molecule compounds. Science, 341: 651-654

[38] Dowey SN, Huang X, Chou BK, Ye Z, Cheng L (2012). Generation of integration-free human induced pluripotent stem cells from postnatal blood mononuclear cells by plasmid vector expression. Nat Protoc, 7: 20132021

[39] Pruszak J, Sonntag KC, Aung MH, Sanchez-Pernaute R, Isacson O (2007). Markers and methods for cell sorting of human embryonic stem cell-derived neural cell populations. Stem Cells, 25: 2257-2268

[40] Jonsson ME, Ono Y, Bjorklund A, Thompson LH (2009). Identification of transplantable dopamine neuron precursors at different stages of midbrain neurogenesis. Exp Neurol, 219: 341-354

[41] Xi J, Liu Y, Liu H, Chen H, Emborg ME, Zhang SC (2012). Specification of midbrain dopamine neurons from primate pluripotent stem cells. Stem Cells, 30: 1655-1663

[42] Chung S, Moon JI, Leung A, Aldrich D, Lukianov S, Kitayama Y, et al. (2011). ES cell-derived renewable and functional midbrain dopaminergic progenitors. Proc Natl Acad Sci U S A, 108: 9703-9708

[43] Vierbuchen T, Ostermeier A, Pang ZP, Kokubu Y, Sudhof TC, Wernig M (2010). Direct conversion of fibroblasts to functional neurons by defined factors. Nature, 463 : 1035-1041

[44] Sheng C, Zheng Q, Wu J, Xu Z, Sang L, Wang L, et al. (2012). Generation of dopaminergic neurons directly from mouse fibroblasts and fibroblast-derived neural progenitors. Cell Res, 22: 769-772

[45] Caiazzo M, Dell'Anno MT, Dvoretskova E, Lazarevic D, Taverna S, Leo D, et al. (2011). Direct generation of functional dopaminergic neurons from mouse and human fibroblasts. Nature, 476: 224-227

[46] Liu X, Li F, Stubblefield EA, Blanchard B, Richards TL, Larson GA, et al. (2012). Direct reprogramming of human fibroblasts into dopaminergic neuron-like cells. Cell Res, 22: 321-332

[47] Liu X, Huang Q, Li F, Li CY (2014). Enhancing the efficiency of direct reprogramming of human primary fibroblasts into dopaminergic neuron-like cells through p53 suppression. Sci China Life Sci, 57: 867-875

[48] Pfisterer U, Kirkeby A, Torper O, Wood J, Nelander J, Dufour A, et al. (2011). Direct conversion of human fibroblasts to dopaminergic neurons. Proc Natl Acad Sci U S A, 108: 10343-10348

[49] Sheng C, Zheng Q, Wu J, Xu Z, Wang L, Li W, et al. (2012). Direct reprogramming of Sertoli cells into multipotent neural stem cells by defined factors. Cell Res, 22: 208-218

[50] Wu J, Sheng C, Liu Z, Jia W, Wang B, Li M, et al. (2015). Lmxla enhances the effect of iNSCs in a PD model. Stem Cell Res, 14: 1-9

[51] Lujan E, Chanda S, Ahlenius H, Sudhof TC, Wernig M (2012). Direct conversion of mouse fibroblasts to selfrenewing, tripotent neural precursor cells. Proc Natl Acad Sci U S A, 109: 2527-2532

[52] Kim SM, Flasskamp H, Hermann A, Arauzo-Bravo MJ, Lee SC, Lee SH, et al. (2014). Direct conversion of mouse fibroblasts into induced neural stem cells. Nat Protoc, 9: 871-881

[53] Kim J, Efe JA, Zhu S, Talantova M, Yuan X, Wang S, et al. (2011). Direct reprogramming of mouse fibroblasts to neural progenitors. Proc Natl Acad Sci U S A, 108: 78387843

[54] Wang L, Huang W, Su H, Xue Y, Su Z, Liao B, et al. (2013). Generation of integration-free neural progenitor cells from cells in human urine. Nat Methods, 10: 84-89

[55] Thier M, Worsdorfer P, Lakes YB, Gorris R, Herms S, Opitz T, et al. (2012). Direct conversion of fibroblasts into stably expandable neural stem cells. Cell Stem Cell, 10: 473-479

[56] Han DW, Tapia N, Hermann A, Hemmer K, Hoing S, Arauzo-Bravo MJ, et al. (2012). Direct reprogramming of fibroblasts into neural stem cells by defined factors. Cell Stem Cell, 10: 465-472 